\title{
Series of Nine Cases of Axial Displacement of Distal Tibial and/or Fibular Shafts from Aircraft Crashes with Proposal of Potential Mechanisms
}

\author{
Stephen L Richey, Katrina Richey
}

Kolibri Aviation Safety and Survivability Research, Indianapolis, United States

\begin{abstract}
:
Previously, a pair of aircraft crash fatalities was reported by Byard and Tsokos involving extreme trauma to the lower legs with avulsion of the musculature and extrusion of the distal tibial shaft through the inferior aspect of the feet and shoes. This report was important to both the forensics and the injury prevention fields because it demonstrates a finding that may help to indicate not only the severity and nature/direction of an impact but also the position of the extremities at the time of collision with the terrain. Thus, here are reported an additional nine cases out of a larger series of 1182 aircraft fatalities (0.7\%) with similar findings and discuss the biomechanical origins of such injuries.

Keywords:
\end{abstract}

fracture; talus; aircraft crash; tibia; trauma

\section{INTRODUCTION}

The impacts and decelerations associated with aircraft crashes are relatively frequent sources of severe traumatic injuries as has been previously discussed in the literature. (Siegel and Mohler, 1970; Wagner, 2005; Folio et al, 2009; Mirzatolooei and Bazzazi, 2013; Wiegmann and Taneja, 2003; Taneja and Wiegmann, 2003; Vidoli and Mundorff, 2012) Among the most frequent forms of trauma seen in aircraft crashes are fractures and associated soft tissue trauma of the lower extremities.(Mirzatolooei and Bazzazi, 2013; Wiegmann and Taneja, 2003; Taneja and Wiegmann, 2003). The ramifications of these forces can be extreme and dramatic especially in the crashes with the highest impact velocities or shortest deceleration distances. One example of this was the report by Byard and Tsokos on the inferior avulsion of the tibial shaft through the feet and shoes of victims. (Byard and Tsokos 2006) Here we report an additional nine cases of this unusual injury.

\section{METHODS}

This paper is an outgrowth of a project that started as an undergraduate student research project at Saginaw Valley State University during the time one of the authors (SLR) was affiliated with that institution (2007 to 2009). As part of an effort to create a broader and more complete picture of injury patterns resulting from aircraft crashes and the mechanisms behind them as well to help identify prevention methods that might reduce the frequency and severity of such injuries in crashes in the future, requests for copies of autopsy and investigation reports were sent out to coroners and medical examiners across the United States. When received, these were matched with data from the combined investigatory efforts of the Federal Aviation Administration and the National Transportation Safety Board (NTSB) using the online agency databases and the NTSB Docket Management System. Additional data was also obtained in several cases from local law enforcement investigation reports. The crash characteristics are logged into a database using, in part, the Lamb-Baker Air Crash Taxonomy developed by
Baker and Lamb. (Baker and Lamb, 1991; Baker et al, 1993, 1995, 1996, 2001; Li et al, 2002). In total to date, data for 1784 cases has been received involving aircraft ranging from ultralight aircraft to heavy wide body airliners ("jumbo jets") and includes fixed-wing aircraft, elicopters and gyrocopters. 602 of the cases had to be excluded from initial review due to incomplete, unclear or insufficient information that prevented their inclusion in this paper.

Reports and, when available, photographs were examined for cases where the tibial shafts were displaced inferiorly through the bottoms of the feet as previously described in the case reported by Byard and Tsokos. Cases were initially selected based upon the presence of lacerations or avulsions of the plantar surfaces of the feet, fractures of the bones of the feet or ankle and then were further reviewed to identify those cases where specific documentation of the tibial or fibular shafts being displaced through the feet was present. In any case where equivocal documentation existed, the medicolegal agency which provided information for the case in question was contacted for clarification.

There are several limitations to this study insofar as the approach to providing a complete picture of the population is concerned. The primary issue is the refusal of several jurisdictions to provide reports as a result of regulatory limitations on release of data. This is an issue that significantly impacts not only this project but also other epidemiology or biomechanics projects. It is important that researchers work together with the legislators and other officials to assure that there is a research exemption or workaround to allow access to this vital information. Another issue that comes up in discussion of aircraft crash injury biomechanics is the decision to only autopsy those victims who had direct access to the controls of the aircraft or those bodies requiring scientific methods of identification. Doing so negates the ability to obtain accurate data, especially if one is interested in improving the safety of passengers. The best practice is to autopsy all victims for three reasons. The first is to assure that the correct body is returned to the correct family. (Hulsey, 2013) The second is to ensure that everything possible is learned from the loss of valuable members of society that may prevent such occurrences in the future. The final reason is perhaps the most 
forensically important reason. That is the standpoint of producing an honest and forthright investigation is to rule out the possibility of a medical issue with a passenger as a precipitating event in the crash.

\section{CASE REPORTS}

\section{CASE 1}

The 58 year old male victim was the pilot of an aerobatic jet aircraft that impacted the ground and trees while performing in an air show. The crash produced a crater approximately four feet deep by 60 feet wide and 100 feet long followed by a 150 yard long debris field. The cockpit was largely disintegrated and burned following impact. The pilot was wearing a helmet and was restrained with a five-point harness which is standard on this aircraft The body was noted to have suffered massive trauma with multiple parts either mangled or missing. The right lower extremity was found separated from the trunk and was described by the pathologist being "mostly destructed". The left lower extremity exhibited a similar severe degree of injury but was still attached to the trunk. The dorsal surfaces of the feet were noted to have been partially spared from the mutilation noted on other parts of the body. This may be in part due to the boots the deceased was found wearing. However, multiple fractures of the bones of the feet were noted as were large lacerations of the soles of the feet bilaterally. On the left, an unspecified length of tibia was noted to be protruding through the aforementioned laceration.

\section{CASE 2}

A 32 year old male pilot and a 40 year old passenger were killed when their Piper PA-28-180 single engine light aircraft broke up in flight after an encounter with severely turbulent weather. The aircraft struck the ground and suffered severe damage in the process. According to the National Transportation Safety Board report on the crash due to the effects of a postcrash fire, it was not be determined if the occupants were restrained at the time of the fatal events. Multiple extremity fractures were noted in both victims. The pilot was found to have the distal portion of his left tibia and fibula protruding through medial aspect of the sock and shoe on the left foot.

\section{CASE 3}

A Piper PA-24-250 Comanche single engine light aircraft was taking off from an airport when it experienced a partial loss of engine power. An emergency landing in rolling terrain was attempted and the aircraft struck a hill. The 63 year old male pilot and the 67 year old male right front seat passenger were killed. Two rear seat passengers survived with serious injuries. The pilot died as a result of head and neck trauma. An open fracture of the left ankle which resulted in the distal left tibia "protruding through the heel" was noted at autopsy.

\section{CASE 4}

The 49 year old male pilot and 34 year old male pilot-rated passenger were killed in a Vari-Eze homebuilt aircraft that crashed an open field while they were performing aerobatics at relatively low altitude. The elder pilot was in the front seat of the aircraft which has a tandem seating arrangement. An on-board global positioning system (GPS) recording the flight had a last data point associated with a ground speed of 68 knots which should be a reasonable approximation of the aircraft's speed at the time of impact. Images of the crash taken by the medicolegal investigators were provided by the local jurisdiction and reveal near total disintegration of the aircraft which is built from an room-temperature cured fiber-reinforced plastic composite. Such damage would have resulted in the pilots being exposed directly to the force of the impact with the ground.

The pilot was noted to have a massive multiple trauma including fragmentation. The left hemipelvis and left leg were amputated with externalization of the small bowel, portions of the liver and the gallbladder. The amputated left lower extremity had fractures of all the long bones and extensive degloving of the thigh and knee. The left knee was disarticulated. The right lower extremity suffered a fracture of the femoral head and neck.

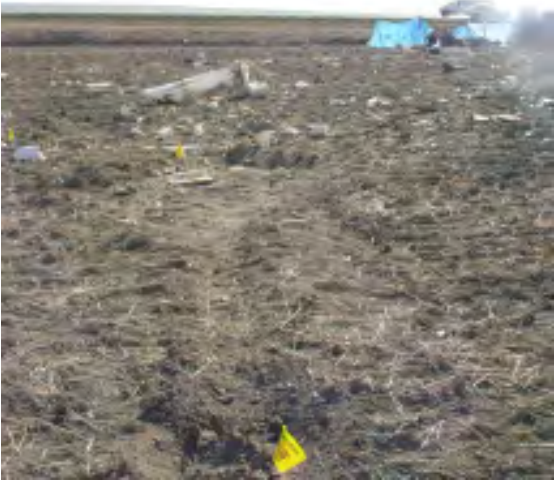

Figure 1: The near-total destruction of the composite materials composing the aircraft in Case 4 contributed to the severity of the injuries in this case.

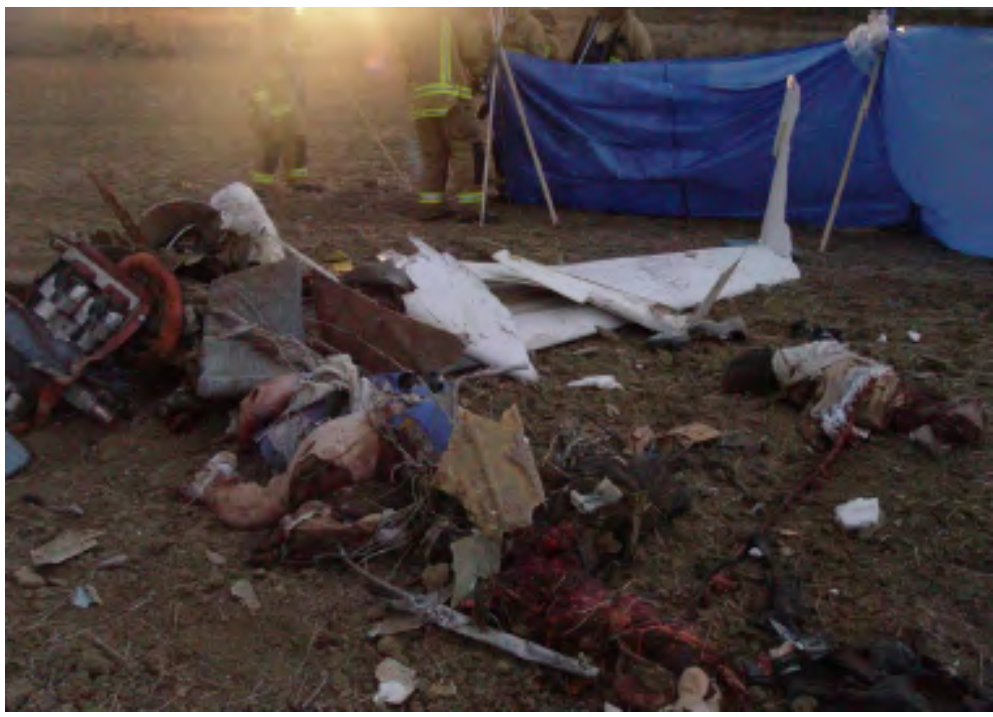

Figure 2: The disintegration of the cockpit of the aircraft involved in Case 4- despite the relatively low speed of the impact- resulted in both victims being ejected from the aircraft during the crash sequence. 
Gaping lacerations were present from the thigh to the ankle. Along with disarticulation of the knee, there was a comminuted fracture of the distal tibia and fibula. Most noteworthy, the distal tip of the right fibula was found to be protruding several inches through a laceration of the sole of the foot. This is visible in Figure 3.

\section{CASE 5}

A 47 year old male crashed in a Beechcraft F33A light aircraft in foggy weather. The aircraft struck the athletic field at a high school in a steep descent at high speed. Examination of th body revealed massive mangling injury. The medial aspect of the right shoe had a fragment of bone embedded in it. This was described by the pathologist handling the case as "fragments of femur". A photograph provided to the authors revealed that the bone appears to have come from within the shoe and is, in fact, likely tibial shaft which had been directed anteriorly and medially by the thick sole of the shoe after it penetrated the other bony structures and soft tissues of the posterior foot. This can be seen in Figure 4.

\section{CASE 6}

The Mitsubishi MU-2B-40 twin-engine turboprop aircraft, piloted by a 74year old male and carrying the pilot's wife was observed by witnesses in a steep dive towards the ground before impacting at a very high rate of speed and in a near vertical attitude. The impact was sufficient to bury the entire forward section of the aircraft into the ground. The pilot's remains were found buried two to four feet below the surface within the resulting crater in a very fragmented state as were those of his wife. Multiple transections of the spine were noted but otherwise the body was reduced largely to fragments of muscle and bone. The most notable of these fragments was of the left foot which was in a shoe with a thick sole. Bones were noted to be protruding through the sole of this shoe.

\section{CASE 7}

The three occupants of a Cessna 172P being flown on a ferry flight at night were killed when the aircraft struck the side of a mountain. All three occupants were noted to have been ejected from the aircraft. It was never

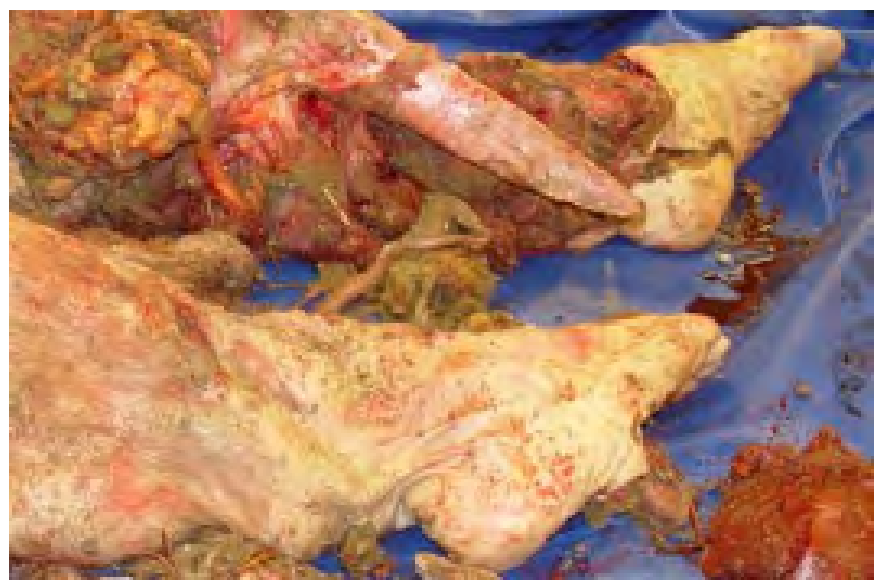

Figure 3: The feet of the victim designated Case 4 reveals the protrusion of bone through the sole of the right foot. determined what, if any, restraints were in use at the time of impact. The 33 year old male pilot's legs were traumatically amputated at the knees and the tibiae and fibulae were fractures bilaterally. The soles of the feet were bilaterally lacerated with shattered bone extruded downward on the right. While all three deaths were the result of massive blunt trauma, only the pilot demonstrated the pertinent fracture complex at autopsy.

\section{CASE 8}

A 69 year old male pilot took off from an airport and the Mustang II aircraft lost engine power while flying near the airport. The aircraft stalled, rolled to the left and departed controlled flight, striking the trees, heavy vegetation and ground in a nose low attitude. The victim was found at the scene with massive head and chest trauma. At autopsy, the legs were noted to be heavily injured. The skin was avulsed from both thighs from the groin to the knee with underlying comminuted fractures of the femurs. Multiple lacerations of the lower legs were present. There was an open comminuted fracture of both ankles. The right heel was lacerated with "bone fragments which have been driven through the skin and the calcaneus".

\section{CASE 9}

A family of three was flying to see relatives in a Cessna R182 when the pilot became disoriented because of clouds and fog while being vectored for an approach to an airport. The aircraft was later found in a heavily wooded swampy area. The wreckage was largely buried approximately 10 feet down into the mud with the tail structures visible above the ground. The victims were a 47 year old male pilot, 44 year old female front seat passenger and an 8 year old male rear seat passenger. All three died from massive blunt trauma. The right front seat female passenger suffered severe widespread disruption in the crash sequence. The lower extremities are multiply injured. The right femur, tibia and fibula at mid-shaft are all fractured. The tibia and fibula were noted to have been driven down through the posterior aspect of the right foot. The left femur was broken just above the level of the knee along with a fracture of the left tibia and fibula just above the ankle. The sole of the left foot was noted to be extensively lacerated with associated fractures of an unspecified nature, but from the documentation, it would appear this was not a fracture complex of the type seen on the right.

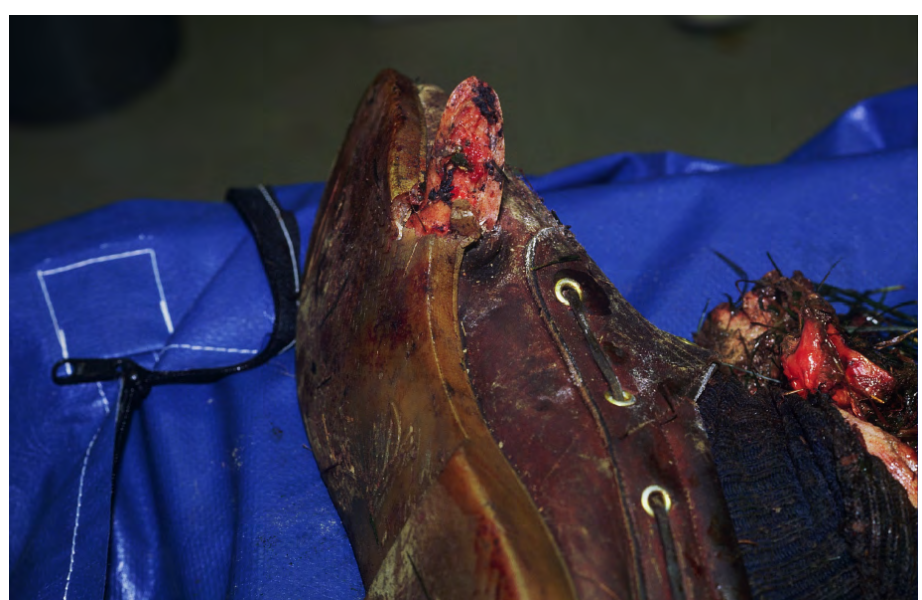

Figure 4. Penetration of the medial aspect of the sole of the right shoe by a fragment of bone in Case 5 . 


\section{DISCUSSION}

\section{Potential biomechanics of the fracture complex}

The actions of the pilot at the moment of impact may have a role to play. If a full deflection rudder input is being applied at the moment of impact it could produce an positioning of the foot and ankle that contributes to the formation of the fracture complex. This could happen in an attempt to regain control of the aircraft that is in a spin before impact or to avoid a collision with terrain since the use of the rudder is necessary to main a coordinated turn. This would produce a marked plantar flexion of the foot (mostly likely in the range of 35-50 degrees) which would more readily transmit forces longitudinally along the metatarsal. (Smith et al, 2005) This plantar flexion would likely be most pronounced in shorter individuals because of the need to lift the foot up to maximize the range of motion as has been reported in the automotive literature. (Crandall et al 1996b) The major biomechanical implication of this plantar flexion are such that it would seem to reduce the chance of producing the fracture complex.

As Smith et al (2005) described, such a position would tend to predispose towards Lisfranc injuries (dislocation or fracture of one or more of the metatarsals from the tarsals), metatarsal fractures and ligamentous disruptions of the midfoot rather than producing injuries to the posterior foot. Tibiotalar dislocation with or without fracture is another possibility if the foot if forced further into more severe degrees of plantarflexion. (Fonda, 1952) Wilson et al described that shorter individuals also experienced higher peak decelerations when there is an intrusion of the dashboard, pedal or toe pan in automobile crashes.(Wilson, 2001) It seems reasonable to postulate that something similar occurs in aircraft crashes.

These factors, particularly with regard to the design of the rudder pedals, may have a significant effect on the rate of the fracture complex and, at least partially, explain its relative rarity compared to other severe injuries of the lower leg. It was pointed out by Dummit and Reid in the 1960s that comminuted tibial fractures which might be more traditionally described as a form of "control surface injury" by some were only identifiable in their series of crash victims in cases where the aircraft involved was a helicopter and not a fixed wing aircraft and when the aircraft impacted upright rather than inverted. (Dummit and Reid, 1969) This latter finding may be potentially important as it could indicate that the mechanism for these injuries, and potentially the fracture complex, involves the direct impact and/or collapse of the forward structures around the feet and lower legs as much as it does transmitted forces through the rudder pedals.

As previously mentioned, the majority of the fracture complexes in our series were in pilots rather than passengers. This is in line with what has been noted in motor vehicle crashes where fractures of the distal legs are more common amongst drivers. (Daffner et al, 1988) A common application of a similar concept in aircraft crashes is a search for fractures of the hands and feet (Wagner, 2005; Folio et al, 2009; Kubat et al 2014) that are supposedly attributable to the forces being applied to the control yoke/column/stick or the rudder pedals at the moment of ground contact and the resulting counter-forces associated with the impact. While it might be appealing to attempt to attribute such injuries to the lower extremity as being from interaction with the rudder pedals, it is important to recognize the limitations of a small series such as this. Further research is needed before this possibility can be assessed and applied with a reasonable degree of scientific certainty.
The preponderance of the affected being pilots may simply be a result of greater exposure (i.e., there may be more pilots in the study population) or the fact that pilots, seated further forward in the vast majority of aircraft than the passengers are likely exposed to higher crash impulses and/or a greater degree of structural collapse. While very little research on this subject matter specifically pertaining to aircraft crashes, the automotive crash survivability and injury biomechanics literature is full of papers discussing the mechanisms of leg, foot and ankle injury in frontal impacts. (Crandall et al 1996a; Crandall, 1996b; Crandall and Martin, 1997), Crandall et al, 1998, Daffner et al, 1988; Dischinger et al, 1994; Ivarsson et al, 2008; Pilkey et al, 1994; Smith et al, 2005; States, 1986; Wilson et al, 2001)

Enough basic similarities exist between the aviation and automotive areas to take the existing literature into consideration. The issue of pedalfoot interaction remains confounding and muddled at present although some basic conclusions can be made (Crandall 1998; Pilkey et al, 1994; Hoyer et al, 2012). When one is considering fractures of the calcaneus, pilon or talus, Morris and colleagues pointed out that the relation of the foot to the pedals had no significant contribution to these injuries. They did point out however, that malleolar injuries and fractures of the forefoot were tied to the interplay of the foot with the pedals. They suggest that malleolar fractures are likely induced by the feet sliding or rotating off of the pedals. Forefoot injuries likely result from a more direct impact loading of the foot by the pedal during the crash sequence. (Morris et al, 1997)

One key difference between the automotive and aviation realms that should be taken to account when attempting to extrapolate data is that while- in most vehicles- the driver is only utilizing one of his feet (most often the right), in an aircraft the pilot would have both of his feet on the rudder pedals especially while maneuvering or during landing or takeoff. Another point to keep in mind is that in most aircraft, there is a second set of rudder pedals in the footwell of the right front or rear seat in the case of tandem seating. This may prove problematic in determining mechanisms of injury or which occupant was actively manipulating the controls in certain circumstances. Of course, the possibility of an occupant having their feet braced against other cockpit or cabin structure in anticipation of the impact is one that must be considered. An additional confounding biomechanical variable is that some pilots may fly with their feet not fully centered on the rudder pedals as the layout in some aircraft leaves pilots the option to fly with their forefoot on the pedal and heel below it where it may or may not be in contact with the floor of the aircraft. If an aircraft is on autopilot, as is increasingly common on cross-country trips in light aircraft, the pilot may not have his feet on the pedals at all if the crash impact is unexpected as it might have been in Case 7.

Such a "half-on, half-off" position, where the inferior aspect of the rudder pedal may be positioned relatively far forward along the plantar surface of the foot, may have one or two possible effects with regard to fracture development. The first is the force may be transmitted directly to the area of the mid- and forefoot rather than the entire foot which would cause a forced dorsiflexion of the foot. This may predispose to fractures of the talus which may be vital in the development of the fracture complex.

When considering the potential biomechanics of an injury such as the fracture complex, it is important to consider not only the evidence at hand but also what has been learned from other injury patterns to the same portions of the body. In this case, it is worth noting the automotive safety literature indicates that distal injuries to the lower extremities are more likely 
to result from longitudinal compressive forces in nature versus proximal fractures which tend to be the result of perpendicular impact loading. (Fildes et al, 1997) This, along with the very nature of the fracture complex, it would appear that longitudinal loading with a minimal torsional load to the tibial shaft is likely involved. If the foot/ankle/leg region is subjected to any significant torsion or bending forces it is unlikely that the complex would be able to occur prior to mechanical failure of the tibial shaft.

A foot planted firmly against a flat surface with the ankle squarely centered may be a prerequisite for the injury to develop as opposed to another form of fracture or dislocation. The other options may result from buckling of the ankle joint to one side or the other due to uneven loading or due to the presence of concomitant lateral loads. When bending loads predominate, as is likely the case in most frontal impact scenarios (Ivarsson et al, 2008) largely as a result of the curvature of the tibia along its long axis (Funk et al, 2004), the scenario is more likely to yield a more 'classic' presentation of tibial shaft fracture. The distal third of the tibial shaft, because of its thin cortical walls and smaller circumference, is likely less resistant to bending forces than its more proximal counterparts although the actual determination of fracture location is dependent upon several other factors as well.

The lack of torsional or perpendicular loading may be what allows the tibia to remain relatively intact as it spears down through the bones of the posterior foot. This scenario would fit with the recognition of a similar injury in a victim of a feet first landing from long fall off of a building. (Buschmann and Tsokos, 2011) Any complicating fractures of the tibia above this could theoretically be the result of continued compressive loading after the tibial shaft has penetrated or application of torsional or perpendicular forces late in the impact sequence. The lack of more significant shortening of the lower leg than is present in most cases reported upon thus far is probably an indicator that the tibial shaft remains largely intact until after the foot is penetrated. If the failure of the shaft occurred earlier in the sequence, it would stand to reason that the bone fragments would tend to take a path of lesser resistance such as telescoping past one another (with or without further comminution) or penetrating through the skin as opposed to being rammed through the denser skeletal structures of the posterior foot.

It would be interesting, going forward, to analyze the related injuries to see if there is a reproducible progressive continuum of injury that culminates in the full fracture complex. It may be that there are intermediate levels of damage such as a collapse of the arches of the feet as was noted in one case in our database. Similarly, there may be a connection between the mechanism for this particular injury and the previously described "aviator's astragalus" which is a group of related fractures and dislocations of the talus that was described in great detail for the first time among military flight personnel who had survived crashes during World War II. (Coltart, 1952) The downward penetration of the tibia combined with compressive loading of the foot in an inferior to superior direction would likely result in the fracture of the neck of the talus or comminution of the body of the talus. Coltart also described avulsive fractures of the inferior tibial margins in his series which may represent an early stage in the creation of the full fracture complex we are describing here. It may be that, given further research into the subject, we may eventually be in a position to link these injuries together along a specific continuum of injury to the foot and lower leg.

It is worth noting that the potentially weakest parts of the bones underlying the tibia are in fairly close association in the vertical axis. The head and neck of the talus is slightly anterior and superior to the sustentaculum tali, the medial projection of the calcaneus. It has been demonstrated that the body of the calcaneus will fail in $50 \%$ of cases under a load above 6.2 $\mathrm{kN}$ which is equivalent to roughly 8 times the average body weight of an adult. (Ramasamy et al, 2011b; Yoganandan et al, 1997) A compressive loading along the long axis of the tibial shaft through the foot would, at least in theory potentially cause a fracture with posterior displacement or rotational displacement of the body of the talus following failure of the neck. Dorsiflexion of the foot may occur through interaction either with the rudder pedals. Narrow structures, such as the rudder bars common at the time of the Coltart series, focus transmitted forces directly to the posterior arch and the navicular and talus which may significantly contribute to this potentially requisite failure of the structures of the posterior foot. However, with current information the most correct statement that can be made is that displacement or disruption of the head of the talus may or may not be a requisite for this potential mechanism.

Compressive failure with comminuted fracture of the body of the talusthrough the trochlea which is directly articulated with the malleoli of the tibia and fibula- is another potential mechanism to be considered if the sustentaculum is a significant factor in this process. A similar mechanism with regard to talar fracture exists in the literature regarding long falls with regard to the so called "dome fracture". (Mukherjee and Young, 1973) The load could then be passed largely to the sustentaculum which may fail allowing for the full fracture complex to develop. Such a path would also potentially explain why both in this series and in the long fall case described by Buschmann and Tsokos (2011), penetration of the fractured bone through the soles of the feet was noted to be on the medial aspect of foot in cases where such details were noted. It could simply be a matter that the posterior foot is weaker with regard to compressive loading on its medial aspect.

One factor which may contribute to the creation of this particular form of lower extremity injury is the presence of boots or other similar footwear which extend above the ankle joint. This was noted in at least one case here (Case 1) and one in the prior literature (Buschmann and Tsokos, 2011). Such a situation could allow the foot and lower leg to maintain their alignment more readily than they might otherwise. It has also been previously reported that boots may have a greater tendency to provide fixation of the foot and less movement of the ankle joint than other forms of footwear. (Eisele et al, 1983; Eillison, 1977) This could conceivably allow for the longitudinal forces necessary for the fracture complex to be maintained longer.

In this way, the sequential failure of bones that are likely necessary for the fracture complex may be a variation on the theme previously described in ships and vehicles struck from underneath by explosive detonations which has been termed "deck-slap injury". These injuries have characteristically been described as fractures of the calcaneus, tibia and knees (Keating, 1944; Barr et al, 1946; Bluman et al, 2010; Ramasamy et al, 2011a; Commandeur et al, 2012; O'Connor, 1968) but images depicting injuries consistent with the fracture complex as a result of explosions during the Global War on Terror have been presented at a forensic radiology conference. (Harcke, 2013) The key difference between explosive and impact induced fractures may be nothing more than the direction of the force. Explosive 'deck-slap" injuries tend to be produced in buckling of the vehicle floor by vertical forces whereas the possibly comparable findings in crashes of aircraft would be more likely secondary to a combination of longitudinal deceleration of the occupant and compressive failure of the footwell of the aircraft. Further 
research and experimental testing on the matter could help to clarify this possible relationship.

It is potentially very important to injury biomechanics researchers and others who may be seeking to reconstruct the circumstances of a crash and the origins of the injuries that resulted there from that the direction of fracture displacement (if any) is noted. Photographs from multiple angles and full body X-rays or, at a very minimum, of areas where fractures are located by other means is an excellent way to achieve this. Without such information, it may be difficult- if not outright impossible- to draw meaningful conclusions as to the validity of the mechanism(s) proposed in this paper. When such information is available in the case of direct impact injuries, it is usually possible to determine a great deal of information about the mechanics of the fracture and, therefore, potentially identify the structures responsible for the impact. (Rabl et al, 1996)

\section{Effects of aircraft design}

The structural integrity of the cockpit must be considered with regard to injury production. It is worth noting that in this series, all occupants were front seat occupants which would at least theoretically result in their being exposed to greater impact and deceleration forces than occupants in seats further aft in the aircraft might be. For six of the nine victims, it was possible to determine which side the aircraft they were occupying. In five of these, the fracture complex was noted to be on the "outboard" limb. The leg that is outboard is potentially less well protected from structural collapse and buckling than the inboard extremity. (Crandall and Martin, 1997; Dischinger et al 1994; Crandall et al 1996a) Two of the remaining cases (Cases 1 and 4 respectively), involved tandem seating equipped aircraft where either lower extremity would be- at least theoretically presuming all other factors are equal- exposed to the same level of risk of the injury in question (see Table 1). This may have forensic implications if questions arise regarding which occupant was in which seat.
While at first it may seem like the fracture complex discussed here is an injury associated with non-survivable forces, it is worth noting that one of the cases presented here had survivors from the crash. In that event (involving case \#3), the rear seat occupants lived through the crash with serious injuries. The comment that one or both of the front seat occupants might have survived if not for lack of shoulder harnesses in the aircraft was made by the pathologist who handled the autopsies on both cases. The best recommendation that can be given with regard to prevention of future cases among the large proportion of general aviation aircraft crashes which involve forces which are within the human tolerance limits for survival (albeit often with serious injury) is to reinforce the footwell of future aircraft to minimize collapse and entrapment.

As pointed out in the automotive literature, significant forces on the tibia can be produced as the foot is trapped between the dashboard (or in the case of an aircraft, the instrument panel) and the crumpling footwell. (States, 1986) An interesting point from the blast injury literature points out that non-failure level deflection of the floors of occupied vehicles may produce severe injuries to both the legs and spine. (Ramasamy et al, 2009)

\section{CONCLUSIONS}

We have reported upon a type of severe foot, ankle and lower leg fracture and offer a biomechanically derived mechanism for its development among the victims of aircraft crashes. Beyond the description of the fracture, there are broader implications that should be kept in mind. The combination of serious injuries and collapse of structures indicate the cockpits of most light aircraft inadequate with regard to occupant protection largely as a result of a lack of focus on crash survivability by aircraft manufacturers and government regulators. This is one area where continued research and testing of new safety systems may yield great benefits in future crashes. Improved documentation by the National Transportation Safety Board and their counterparts- or provision of crash survivability investigations by an

Table 1. Demographics, seating location and injury distribution among victims

\begin{tabular}{|c|c|c|c|c|c|c|c|c|}
\hline Case & Age and Gender & Pilot or Passenger & Side of Aircraft & $\begin{array}{c}\text { Front or Rear } \\
\text { Seat }\end{array}$ & $\begin{array}{c}\text { Fracture Complex } \\
\text { on Left }\end{array}$ & $\begin{array}{c}\text { Fracture Complex } \\
\text { on Right }\end{array}$ & $\begin{array}{c}\text { Affected Aspect } \\
\text { of Heel }\end{array}$ & Footwear \\
\hline 1 & 58/Male & Pilot & Center & Front & $x$ & & NOS & Boots \\
\hline 2 & 32/Male & Pilot & Left & Front & $x$ & & Medial & Athletic shoes ("sneakers") \\
\hline 3 & 63/Male & Pilot & Left & Front & $x$ & & NOS & Not documented \\
\hline 4 & 49/Male & Pilot & Center & Front & & $x$ & NOS & None with body \\
\hline 5 & 47/Male & Pilot & Left & Front & & $x$ & Medial & Shoes, NOS \\
\hline 6 & 74/Male & Pilot & Left & Front & $x$ & & NOS & Shoes, NOS \\
\hline 7 & 33/Male & Pilot & Unknown & Front & $x$ & & NOS & None with body \\
\hline 8 & 69/Male & Pilot & Left & Front & $x$ & & NOS & Shoes, NOS \\
\hline 9 & 44/Female & Passenger & Right & Front & & $x$ & NOS & None with body \\
\hline
\end{tabular}

NOS $=$ Not otherwise specified 


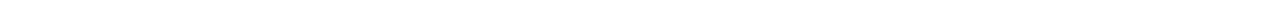

independent third-party organization- may be necessary for research to truly reduce the morbidity and mortality associated with aircraft crashes.

\section{ACKNOWLEDGMENTS:}

The authors would like to thank the coroners and medical examiners who so graciously provided the data for our research project. We also extend our gratitude to Tim Noonan, Dr. Michael LeWitt, Ms. Jules K. Scadden, Mrs. Jennifer Ann Christian-Sebring, Dr. Dave Dufeau and Ms. Charlene Morris for their review and suggestions for the improvement of the article prior to its submission. Some of the photographs in this article were kindly made available by Dr. Thomas Andrew and Ms. Kim Fallon of the New Hampshire Office of the Chief Medical Examiner and through the assistance of the New Hampshire State Police Forensic Laboratory staff. The remaining photos were provided by Drs. Patrick Allen and John Carver and Ms. Debbie Reisdorff of the Larimer County (Colorado) Office of the Coroner/Medical Examiner.

We would also like to thank the reviewers and editorial staff for their help in guiding this paper from its initial format into its final version.

\section{REFERENCES}

Baker SP, Lamb MW: Human factors in crashes of commuter airplanes and air taxis. Washington, DC: Federal Aviation Administration. Contract DTF A01-90-c-00046. 1991.

Baker SP, Lamb MW , Li G, Dodd R.S:Human factors in crashes of commuter airplanes. Aviat Space Environ Med 199364 (1): 63-68.

Baker SP, Li G, Lamb MW, Warner M: . Pilots involved in multiple crashes: "accident proneness" revisited. Aviat. Space Environ Med 199566 (1), 6-10.

Baker SP, Lamb MW, Grabowski JG, Rebok GW, Li G: Characteristics of general aviation crashes involving mature male and female pilots. Aviat Space Environ Med 2001 $72(5), 447-452$.

Baker SP, Lamb MW, Li G, Dodd RS: Crashes of instructional flights. Aviat Space Environ Med 1996; 67 (2): 105-110.

Barr JS, Draeger RH, Sager WW. Blast personnel injury; a clinical study. Mil Surg. 1946;98:1-12.

Bluman EM, Ficke JR, Covey DC. War wounds of the foot and ankle: causes, characteristics, and initial management. Foot Ankle Clin. 2010; 15:1-21.

Buschmann C, Tsokos M: Injury pattern after a fatal feet-first fall from a building. Forensic Sci Med Pathol 2011; 7:369-370

Byard RW, Tsokos M: Avulsion of the distal tibial shaft in aircraft crashes: a pathological feature of extreme decelerative injury. Am J Forensic Med Pathol 2006;27: 337339)

Carr JB: Mechanism and pathoanatomy of the intraarticular calcaneal fracture. Clin Orthop Rel Res. 1993; 290:36-40

Coltart WD: Aviator's Astralagus. J Bone Joint Surg Br. 1952 Nov;34-B(4):545-66.

Commandeur J, Derksen RJ, MacDonald D, Breederveld R: Identical fracture patterns in combat vehicle blast injuries due to improvised explosive devices; a case series. BMC Emergency Medicine 2012; 12:12

Crandall JR, Martin PG, Bass CR, Pilkey WD, Dischinger PC, Burgess AR, O'Quinn TD, Schmidhauser $C B$ : Foot and ankle injury: the roles of driver anthropometry, footwear, and pedal controls, in: 40th Ann. Proc. Assoc. Adv. Automot. Med, 1996

Crandall JR, Portier L, Petit P, Hall GW, Bass CR, Klopp GS, Hurwitz S, Pilkey WD, Trosseille $X$, Tarriere C, Lassau IP: Biomechanical response and physical properties of the leg, foot and ankle. Proc. 40th Stapp Car Crash Conference; SAE Paper No. 962424 1996.

Crandall JR, Martin PG: Lower limb injuries sustained in crashes and corresponding biomechanical research, in: Proceedings of International Symposium on Real World Crash Injury Research, 1997.

Crandall JR, Martin PG, Sieveka EM, et al. Lower limb response and injury in frontal crashes. Accid Anal Prev. 1998;30:667-77.

Daffner RH, Deeb ZL, Lupetin AR, Rothfus WE. Patterns of high-speed impact injuries in motor vehicle occupants. J Trauma. 1988;28:498-501.
Dischinger PC, Burgess AR, Cushing BM, O'Quinn DT, Schmidhauser CB, Ho SM, Juliano PJ, Bents FD: Lower extremity trauma in vehicular front-seat occupants: patients admitted to a level 1 trauma center. SAE Technical Paper \#940710; Warrendale, PA: Society of Automotive Engineers. 1994

Dummit ES, Reid RL: Unique tibial shaft fractures resulting from helicopter crashes. Clin Orthop. 1969; 66:155-8

Eisele JW, Bonnell HJ, Reay DT: Boot top fractures- a forensic masquerade. Am J Forensic Med Pathol. 1983 June; 4(2):181-184

Fildes B, Lenard J, Lane J, Vulcan P, Seyer K. Lower limb injuries to passenger car occupants. Accid Anal Prev. 1997;29: 785-91.

Folio RL, Harcke HT, Luzi SA: Aircraft mishap investigation with radiology-assisted autopsy: helicopter crash with control injury. Aviat Space Environ Med 2009 Apr; 80(4):400-4

Fonda MP: Dislocation of the tibiotalar joint without fracture- an unusual ski injury. J Bone Joint Surg (Br) Jul 1952; 34-A(3):662-662

Funk JR, Rudd RW, Kerrigan JR, Crandall JR: The effect of tibial curvature and fibular loading on the tibia index. Traffic Inj. Prev. 5 (2004) 164-172.

Golano P, Vega J, de Leeuw PAJ, Malagelada F, Manzanares MC, Goetzens V, van Dijk $\mathrm{CN}$ : Anatomy of the ankle ligaments: a pictoral essay. Knee Surg Sports Traumatol Arthrosc (2010) 18:557- 569

Harcke HT: Forensic imaging of blast injuries. RadForensics Conference. Tunica, Mississippi: 2 May 2013.

Hoyer CB, Nielsen TS, Nagel LL, Uhrenholt L, Boel LWT: Investigation of a fatal airplane crash: autopsy, computed tomography and injury pattern analysis used to determine who was steering the plane at the time of the accident. A case report. Forensic Sci Med Pathol 2012 Jun;8(2):179-88

Hulsey L: Families 'grieve over wrong body' in misidentification case http://www. daytondailynews.com/news/news/local/families-grieve-over-the-wrong-bodyinmisidentifi/nNBRh/ Accessed 17 February 2013

Ivarsson BJ, Manaswi A, Genovese D, Crandall JR, Hurwitz SR, Burke C, Fakhry S: Site, type, and local mechanism of tibial shaft fracture in drivers in frontal automobile crashes. Forensic Sci Int. 2008 Mar 5;175(2-3):186-92.

Keating $C$. Wounds in naval action. In: Bailey $\mathrm{H}$, ed. Surgery of Modern Warfare. Edinburgh: E\&S Livingstone; 1944:997-1000

Kubat B, Korthout T, van Ingen G, Louk, A, Rietveld, C, de Bakker HM: Radiological analysis of hand and foot injuries after small aircraft crashes. Forensic Sci Med Pathol. 2014; 10: 351-356

Li G, Baker SP, Lamb MW, Grabowski JG, Rebok GW: Human factors in aviation crashes involving older pilots. Aviat Space Environ Med. 2002; 73 (2), 134-138

Mirzatolooei F, Bazzazi A: Analysis of orthopedic injuries in an airplane landing disaster and a suggested mechanism of trauma. Eur J Orthop Surg Traumatol 2013 April; 23(3):257-62 
Moody GH, Busuttil A. Identification in the Lockerbie air disaster. Am J Forensic Med Pathol. 1994;15:63- 69.

Morris A, Thomas P, Taylor AM, Wallace A. Mechanism of fractures in ankle and hindfoot injuries to front seat car occupants-an in-depth accident data analysis. SAE Technical Paper \#973328. Warrendale, PA: Society of Automotive Engineers. 1997 Mukherjee SK, Young AB: Dome fracture of the talus- a report of ten cases. J Bone Joint Surg (Br) May 1973; 55-B(2): 319-326

O'Connor P: Explosion fractures of heels. Br Med J. 1968 Jun 8;2(5605):624.

Pilkey WD, Sieveka EM, Crandall JR, Klopp GS. The influence of foot position and vehicular intrusion on occupant lower limb injury in full-frontal and frontal-offset crashes. Proceedings of the 14th ESV conference 94-S4-W-31. Munich, Germany; 1994.

Rabl W, Haid C, Krismer M: Biomechanical properties of the human tibia: fracture behavior and morphology. Forensic Sci Int. 1996 Nov 11;83(1):39-49

Ramasamy A, Hill AM, Hepper AE, Bull AMJ, Clasper JC: Blast mines: physics, injury mechanisms and vehicle protection. JR Army Med Corps 2009; 155(4): 258-264

Ramasamy A, Hill AM, Phillip R, Gibb I, Bull AMJ, Clasper JC: The modern "deck-slap" injury- calcaneal blast fractures from vehicle explosions. J Trauma. 2011;71: 1694-1698
Ramasamy A, Hill AM, Gibb I, Bull AMJ, Clasper JC: Blast-related fracture patterns: a forensic biomechanical approach. J R Soc Interface 2011; 8: 689-698 Smith BR, Begeman PC, Leland R, Meehan R,Levine RS, Yang KH, King Al: A mechanism of injury to the forefoot in car crashes, Traffic Inj Prev 2005 6(2): 156-169

States JD: Adult occupant injuries of the lower limb, in: Biomechanics and Medical Aspects of Lower Limb Injuries. Warrendale, PA: Society of Automotive Engineers, Warrendale, PA, 1986, pp. 97-107.

Taneja N, Wiegmann DA. Analysis of injuries among pilots killed in fatal helicopter accidents. Aviat Space Environ Med 2003; 74: 337-41.

Wagner G: Aviation accidents: role of pathologist. In: Payne-James J, Byard RW, Corey T, et al, eds. Encyclopedia of Forensic and Legal Medicine, Vol 1. Elsevier/Academic Press. 2005:243-252.

Wiegmann DA, Taneja N: Analysis of injuries among pilots involved in general aviation airplane accidents. Accid Anal Prev 2003; 35:571-7

Wilson LS, Mizel MS, Michelson JD: Foot and ankle injuries in motor vehicle accidents. Foot Ankle Int 2001; 22:649- 652

Yoganandan N, Pintar FA, Kumaresan S, Boynton M: Axial impact biomechanics of the human foot-ankle complex. J Biomech Eng 1997; 119: 433-437. 